\title{
LETRAMENTO CRÍTICO (VISUAL E RACIAL): DESCONSTRUINDO REPRESENTAÇÕES UNÍVOCAS E SUAS VIOLÊNCIAS
}

Critical Literacy (Visual and Racial): Deconstructing Univocal Representations and Their Violence

\author{
Andréa Cotrim SILVA (UNIP) ${ }^{1}$
}

\begin{abstract}
RESUMO: As práticas do Letramento Crítico e de suas vertentes (Letramento Visual e Letramento Racial) nos servem como um modo de docência que estimula o pensamento reflexivo do aluno, em prol da formação de identidades menos violentas. Isto só pode acontecer mediante a desconstrução dos saberes impostos pela colonização, de suas "verdades universais" como a noção de moderno versus primitivo, bom versus ruim, justo versus injusto, superior versus inferior ou qualquer outra hierarquização de desigualdade, o que acaba gerando a marginalização de certas identidades e seu modo de vida. Pretendemos, à luz de Souza (2016), Vattimo e Zabala (2011), Monte Mór (2018), Collins (2000), dentre outros teóricos da educação, do pós-colonialismo e do feminismo mostrar como diminuir no público a violência da representação cinematográfica hegemônica, em relação a determinados grupos sociais como os afro-americanos, ora legitimando, ora repudiando discriminações interseccionais, apontando para tentativas de rupturas e suas re-partilhas de sentido (RANCIÈRE, 2005). Por extensão, objetivamos um exercício pedagógico crítico que privilegie a expansão de pontos de vista e agência em sala de aula.
\end{abstract}

PALAVRAS-CHAVE: letramento crítico; cinema; educação de língua inglesa; violência; decolonialidade.

\begin{abstract}
The practices of Critical Literacy and its aspects (Visual Literacy and Racial Literacy) serve us as a teaching mode that stimulates the student's reflective thinking, in favor of the formation of less violent identities. This can only happen through the deconstruction of knowledge imposed by colonization, of its "universal truths" such as the notion of modern versus primitive, good versus bad, fair versus unfair, superior versus inferior or any other hierarchy of inequality. This leads to the marginalization of certain identities and their way of life. We intend, in the light of Souza (2016), Vattimo; Zabala (2011), Monte Mór (2018), Collins (2000), among other theorists of education, postcolonialism and feminism, to show how to reduce the violence of hegemonic cinematic representation in the public, in relation to certain social groups like the African-Americans, sometimes legitimating, sometimes disaffirming intersectional discriminations pointing to attempts at ruptures and their "redistributions of meaning" (RANCIÈRE, 2005). By extension, we aim for a
\end{abstract}

\footnotetext{
${ }^{1}$ Professora na Universidade Paulista (UNIP) e Doutora em Letras pela Universidade de São Paulo (USP) no Programa de Pós-Graduação em Estudos Linguísticos e Literários em Inglês. cotrim.andrea@gmail.com
} 
critical pedagogical exercise that privileges the expansion of views and agency in the classroom.

KEYWORDS: critical literacy; cinema; English language education; violence, decoloniality.

A proposta de Letramento Crítico (re)definida por Souza (2016), com base nos ensinamentos de Paulo Freire (1921-1997), nos estimula não somente a decolonizar o pensamento acostumado a categorias fixas de significado, impostas por uma visão ocidentalizada, mas também a rever nossa prática em sala de aula, enquanto docentes que almejam tanto uma reflexão crítica como uma postura ética por parte de nossos alunos, diante das adversidades. Segundo o autor, torna-se um objetivo pedagógico preparar aprendizes para confrontos e conflitos com as diferenças de toda espécie. Para tanto, é preciso sair da sensação de conforto acalentada por nossas verdades pretensamente inquestionáveis e, por consequência, violentas, posto que obliteram outras formas de se ver, sentir e interagir (n)o mundo.

Logo, Letramento Crítico é para Souza senão um processo constante de reflexão sobre um texto (verbal, sonoro, visual etc.) que sabidamente tem origem no contexto de seu autor, interpretado por um leitor, igualmente, produtor de significados e que precisa se tornar autoconsciente da origem de seus pensamentos e valores como tendo sido elaborados em uma coletividade sócio-histórica específica.

Duas das vertentes do Letramento Crítico são o Letramento Visual e o Letramento Racial. Em se tratando do Letramento Visual ou aquele que se presta à análise das imagens, partimos do pressuposto que nenhuma visualidade pode ser transparente ou inconteste; cada intérprete mobiliza sentidos advindos de sua cultura, experiências, valores e crenças para a compreensão dos dados imagéticos que podem, eventualmente, ser reorganizados por um olhar mais atento do objeto. Há, portanto, uma vontade nossa de analisar o visual na sua expansão de sentidos e na miríade de indagações que este processo evoca.

Comecemos pela noção de real, realidade e representação com vistas à representação cinematográfica do Outro não-hegemônico, ou seja, o Outro mulher, quilombola, refugiado, negro(a) ou qualquer um que seja frequentemente figurado às margens, despontando com generalizações excessivas e necessitando travar constantemente uma luta por reconhecimento e dignidade. E, ao falar do Outro que nos é tão diferente e, ao mesmo tempo, tão igual, há de se refletir igualmente sobre o nosso 
locus de enunciação ou o território onde e do qual se fala, suas concessões e vulnerabilidades, subalternidades e privilégios, mediante contextos diversos que só podem ser compreendidos por meio da noção de signo oscilante, conforme explica Souza (2004), citando Bhabha e Bakhtin:

\begin{abstract}
Contrário a uma visão abstrata e idealizada do signo saussuriano que pressupõe uma ligação direta e imediata entre o significante e o significado, ou seja, entre a palavra e o conceito/significado, Bhabha postula algo semelhante ao signo opaco e material bakhtiniano; no conceito de signo abstrato saussuriano, o signo já vem pronto, normatizado e pré- interpretado, não havendo espaço para a variação e para outras interpretações. Enquanto conceito de signo onde a ligação entre o significante e o significado já vem normatizado, ele dispensa, portanto, o lugar do intérprete e a necessidade do trabalho de interpretação. Trata-se de um conceito de signo que não atende à problemática pós-colonial uma vez que tal conceito não dá conta das justaposições conflitantes linguísticas e culturais comuns em tais contextos. Por outro lado, o conceito sócio-histórico do signo bakhtiniano (Bakhtin 1973), prevê que a conexão entre o significante e o significado seja feita indiretamente, mediada por intérpretes ou usuários da linguagem situados socialmente sempre em determinados contextos ideológicos, históricos e sociais, marcados por todas as variáveis existentes nesses contextos (classe social, sexo, faixa etária, origem geográfica etc.). Como tal, o signo bakhtiniano é sempre material, produto de condições determinadas de produção e fruto do trabalho necessário da interpretação. Tal conceito de contexto e de condições sócio-históricas de produção e de interpretação é chamado por Bhabha de locus de enunciação (SOUZA, 2004, p. 08).
\end{abstract}

Deste modo, o signo saussuriano normatiza conceitos, engessando-os, uma vez que não pressupõe o papel do intérprete, nem as condições de produção do significado. As epistemologias que apostam na fixidez do signo e que ditam, arbitrariamente, o que é a verdade acabam por legitimar seu próprio poder (FOUCAULT, 2007), em prejuízo da pluralidade de saberes, culminando no silenciamento do sujeito que, ultrajado em suas opiniões, modos de vida e direitos, não dá a ver sua visão de mundo (VATTIMO; ZABALA, 2011). Este silenciamento do sujeito ocorre porque um significante estável desconsidera, invariavelmente, o consentimento daqueles a quem pretende definir, a exemplo do termo "mulher" que transcende a definição de gênero, dada a sua constituição interseccional de etnia, classe social, escolaridade etc., em diferentes contextos geográficos e históricos. A categoria "gênero", portanto, não vem separada de outras discursividades.

Satya Mohanty (1997, p. 116) corrobora Bhabha, ao explicar que a crítica ao signo saussuriano esbarra no campo político justamente quando destrincha este "social" em coletividades e/ou subjetividades, nos termos mencionados (gênero, sexualidade, raça, classe econômica, faixa etária, origem geográfica, religiosidade) e seus 
significados culturais, fundantes da condição de exclusão e/ou de pertencimento em espaços específicos. São exatamente essas variáveis às quais Bhabha e Mohanty se referem que fazem do signo um predicamento movente e não aleatório. Em outras palavras, não existe relação unívoca entre significante e significado como suposto por Saussure; a noção de signo presume, sim, um contexto de onde intérpretes surgem, estabelecendo elos de sentidos (SILVA, 2017). O processo de significação interconecta significante (palavra, imagem, gesto) e significado (conceito, objeto), mediante um referente cultural e histórico-social.

Já, o signo bakhtiniano concebe as noções de temporalidade e historicidade do significante, exigindo inúmeras releituras do interpretante, dentro de uma teia de significados possíveis, o que implica dizer que a realidade não é uma só e a mesma para todos. O real físico é, eminentemente, a representação da verdade de um grupo e não se constitui senão como um (re)corte simbólico do real ou, analogamente e na esteira de Bakhtin, uma contenção singela da realidade, permeada por incessantes construções sócio-históricas, como já dissemos.

Isto posto, ainda que alguns filmes pareçam ensejar um direcionamento monolítico para os nossos sentidos ou algum tipo de controle simbólico, aos moldes do signo saussuriano, dada uma montagem criteriosa das cenas e de suas sequências, enquadramentos, iluminação, angulação etc., por parte do esforço conjunto de diretores, roteiristas, atores, dentre outros, percepções sequer imaginadas vêm à tona, em virtude do universo particular de cada espectador.

Ainda assim, a questão do modo dominante de representação e de seu caráter político necessita de nossa atenção, pois insiste em um regime estereotipado de certos grupos sociais, cristalizando e disseminando preconceitos, ao que demos o nome de "violência da representação" ou a condição mesma de toda e qualquer tentativa que busca visibilizar alguns grupos, sobretudo formados por pessoas brancas, heterossexuais, euro-estadunidenses e de classe média, invisibilizando outros, a exemplo de indígenas, latinos, afro-americanos, asiáticos, os quais são geralmente assinalados como primitivos, exóticos, tolos, subservientes, caricatos, etc. Seguiremos, então, com uma breve descrição do Outro não-hegemônico, durante algumas décadas da principal indústria cinematográfica mundial e, posteriormente, à sugestão de trabalho destas percepções em sala de aula, convocando os estudos dos Letramentos Visual e Racial. 
As representações desfavoráveis de certos grupos sociais nem sempre passaram despercebidas por teóricos que examinaram produções fílmicas estadunidenses. Indígenas de aldeias diferentes chegaram a reclamar de equívocos culturais e históricos, pois alguns deles eram retratados como guerreiros quando, na verdade, não passavam de fazendeiros pacíficos. Os hispânicos também protestaram, reiteradas vezes, contra o rótulo de preguiçoso, membro de gangue, de "chicano" ultrarreligioso e/ou malintencionado, de revolucionário, toureiro, etc., enquanto suas mulheres eram associadas à dança e à fogosidade. Representações preconceituosas também não pouparam os afroamericanos que desde o tráfico negreiro sofrem com o desejo velado, mas sistêmico ou ad aeternum de dominação (SILVA, 2017, p. 76).

Por sua vez, Giroux (1995) sustenta que a representação do mundo nas telas coloca o negro em severa desvantagem porque embora a violência pareça atravessar designadas fronteiras de classe, raça e espaço social, a representação da violência na mídia popular é vastamente retratada em termos raciais. Deste modo, a compreensão generalizada que se tem é de que a vida urbana está associada aos crimes cometidos pela juventude negra, uma vez que a estética do audiovisual assinala, recorrentemente, a desordem dos guetos, das escolas decadentes, dos professores desanimados, dos arrastões, do desemprego e do ódio social. Todo esse empenho em criminalizar o negro afasta da sociedade branca quaisquer responsabilidades sobre a violência e desigualdades enfrentadas por certos grupos sociais:

Como o contexto e as condições para a produção de representações violentas são justificados em nome do entretenimento e dos lucros de bilheteria alta, os jovens se vêem cada vez mais tanto sujeito como objeto de violência cotidiana e brutalidade (...) a cultura da violência tratada com desdém pela televisão, vídeos e filmes é muito difundida para ser ignorada ou rejeitada (GIROUX, 1995, p. 05).

Quando falamos de violência da representação, não nos restringimos ao âmbito cotidiano da agressão física, da verbal ou da coletiva das guerras; existe uma violência simbólica das relações de poder que se esconde no apagamento d outro quando ele deixa de existir socialmente e não tem o direito de narrar-se ${ }^{2}$. Esta questão é redimensionada por Vattimo e Zabala (2011) quando ambos afirmam que a violência, por si só,

\footnotetext{
${ }^{2}$ Nesse sentido, o estudo sobre "representação da violência" assume uma amplitude considerável, dada à natureza indissociável dos conceitos "representação" e "violência, assim, denominado, por nós, de "violência da representação".
} 
prescinde dos insultos verbais e dos assassinatos sanguinolentos. Bourdieu (1989), ao seu turno, coopera com a noção de violência simbólica, exercida como forma de dominação:

\begin{abstract}
Não basta notar que as relações de comunicação são,de modo inseparável, sempre, relações de poder que dependem, na forma e no conteúdo, do poder material ou simbólico acumulado pelos agentes (ou pelas instituições) envolvidos nessas relações [...]. É enquanto instrumentos estruturados e estruturantes de comunicação e de conhecimentos que os sistemas simbólicos cumprem a sua função política de assegurar a dominação de uma classe sobre outra (violência simbólica) dando o reforço de sua própria força às relações de força que as fundamentam e contribuindo, assim, segundo a expressão de Weber, para a "domesticação" dos dominados (BOURDIEU, 2012, p. 11).
\end{abstract}

Já, para Rancière (2005), a violência complexifica-se nas partilhas desiguais de sentido, pois não temos acesso a tudo; há verdades encobertas, em decorrência de um mecanismo ao qual o autor chama de "polícia". Destarte, criam-se sentidos que são endossados, em detrimento de outros que são ofuscados. Transpondo-nos para o cinema, os valores dominantes da colonialidade e de suas estruturas de poder enaltecem, sobremaneira, a branquitude, desfavorecendo os demais grupos étnicos sutil ou escancaradamente, mas sempre à exaustão, podendo propagar injustiça, ódio racial e descaso, não obstante um enredo despretensioso ou aparentemente desvinculado de alguma ideologia (SILVA, 2017).

Constatamos, desta maneira, que a representação hegemônica do Outro vem, desde o início de Hollywood, na chave essencialista dos sujeitos subalternos, embora tenha havido algumas tentativas de desestabilização.Via de regra, o homem negro dos filmes das décadas de 1910 e 1920 era caracterizado como lascivo, perigoso e causador de intrigas. Tomemos como exemplo O nascimento de uma Nação (1915), de D. W. Griffith, o qual apregoa, tenazmente, um arsenal de falsidades ideológicas, a começar pela inscrição gráfica, já na primeira cena: "O carregamento de Africanos para a América plantou a primeira semente de desunião". Inverdades como esta são agravadas pela atuação jocosa de atores brancos que utilizavam uma técnica chamada blackface, a qual consistia em pintar seus rostos com cortiça queima da para encenar pessoas negras de índole duvidosa. Abaixo, o desenho mostra a representação caricata da população negra, até meados de 1940, quando ainda há uso de blackface. O esquema é uma releitura nossa do signo saussuriano nos sets de cinema, pois relaciona o homem negro a significados restritos, ora como ameaçador, ora como o "preto velho" e servil, de acordo 
REVISTA X, Curitiba, volume 14, n.5,p. 168-180, 2019

com sua compleição física para uma plateia, majoritariamente, branca. Concomitantemente, a mulher que se consagra nas telas é a "Mammy", reconhecida como boa cozinheira, mas rabugenta, ao passo que a mulher negra magra era destinada a papéis que ressaltavam sua sensualidade.

Esquema:

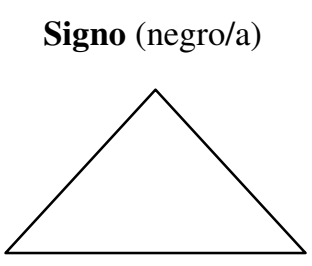

Significante

\begin{tabular}{|l|}
\hline Blackface \\
Homem forte \\
"Preto velho" \\
"Preta velha" \\
Negra jovem \\
\hline
\end{tabular}

\section{Significado}

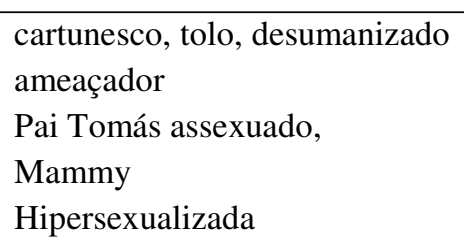

Fonte: $\operatorname{SILVA}(2017$, p.141).

Nos anos posteriores, o negro era extenuantemente estampado como vítima e observador passivo de sua própria saga, ao passo que a representação da mulher negra persistia em atribuições estereotipadas, relacionadas a sua sexualidade exacerbada ou a sua arrogância, supostamente, nata.

Reiteramos que ao longo dos séculos, diretores afro-americanos apostaram incessantemente em produções independentes ${ }^{3}$, as quais não contavam com $o$ investimento de Hollywood. Houve, no entanto, uma re-partilha do sensível, em meados dos anos 1950, quando despontaram atores glamurosos, sofisticados, inteligentes e amáveis como Poitier e Belafonte, responsáveis pela sistematização positiva da negritude, em uma época de militância (não) violenta pelos Direitos Civis. Nos anos 1970, por exemplo, o movimento blaxploitation, inspirado pelas lutas antirracistas dos Panteras Negras e de líderes como Martin Luther King e Malcolm X, da década anterior, havia rearticulado a imagem do homem negro como viril, inteligente $\mathrm{e}$ "descolado", atuando nos espaços de poder e reconhecimento como um detetive ou transitando por lugares de contravenção com relativo prestígio e glamour. A mulher

\footnotetext{
${ }^{3}$ Ler informações mais detalhadas a respeito das tentativas de ruptura da representação hegemônica na tese de doutorado de SILVA, A. A. C. O sensível (não) partilhado: a violência poética e política da (ir) representação do negro em Hollywood, 2017.
} 
negra, no entanto, persistia na figuração sexualizada, embora também ganhasse mais poder e autossuficiência. Já, nos anos 1990, o desafio de diretores como Spike Lee era o de retomar a temática do racismo e de seus efeitos nefastos, enquanto a maioria dos filmes, a despeito dos levantes populares e de outras lutas sociais, sublinhavam o afroamericano como coadjuvante, na chave do "melhor amigo" do branco protagonista. Alguns atores como Eddie Murphy, Wesley Snipes, Whoopi Goldberg e Denzel Washington assumem maior destaque, ocasionalmente, resvalando à estereotipia do negro cômico, atrevido, fanfarrão ou excêntrico.

Mas, a constatação de uma mudança expressiva, deu-se, de fato, durante a Era Obama (2009-2016), em que uma profusão de filmes realça a participação da negritude na causa abolicionista dos séculos XVIII e XIX e na militância pelos Direitos Civis, das décadas de 1950 e 1960. Coincidência ou não, foi durante o governo do primeiro presidente de pele escura nos Estados Unidos que a temática negra torna-se enredo tanto em produções tímidas, como aquelas de orçamento mais robusto. Filmes, séries e documentários ganham as telas. O mordomo da Casa Branca (2013), Doze anos de escravidão (2013), Selma - uma luta pela igualdade (2015), Os oito odiados (2016), O nascimento de uma nação (2016) e Estrelas além do tempo (2017) perfazem o rol de produções do grande circuito ${ }^{4}$, desde a posse de Barack Obama, em 2009. É natural cogitarmos que o contexto político contemporâneo estivesse entrelaçado com a feitura destas obras, de alguma maneira, e que este tivesse mobilizado um campo de sentidos específico. Afinal, é a primeira vez que a narrativa negra avança e pode ser contada como um épico, uma história com suas feridas, porém, exitosa, uma vez que alcança, concomitantemente, na vida real, o cargo mais alto do governo. Neste sentido, há o que Rancière denomina como política ou re-partilha dos sentidos, isto é, o que

rompe a figuração sensível na qual se definem as parcelas e as partes ou sua ausência a partir de um pressuposto que por definição não tem cabimento ali: a de uma parcela dos sem- parcela. Essa ruptura se manifesta por uma série de atos que reconfiguram o espaço onde as partes, as parcelas e as ausências

\footnotetext{
${ }^{4}$ Outros filmes de menor bilheteria sobre a temática negra tomaram as telas, durante a Era Obama: Red Tails (2012), EUA, Direção: George Lucas; For Colored Girls (2010), Canadá, Direção: Tyler Perry; Precious (2010), EUA, Direção: Lee Daniels; Cercas (2016), EUA, Direção: Denzel Washington; Michelle e Obama (2016), EUA, Direção: Richard Tanne; À procura da Liberdade (2016), EUA. Direção: Peter Cousens, além dos documentários What happened, Miss Simone? (2016), EUA, Direção: Liz Garbus, 13th (2016), USA, Direção: Ava DuVernay e das produções televisivas Raízes (2016), EUA. Direção: Bruce Beresford et al e Showing Roots [Raízes de uma amizade] (2016). EUA. Direção: Michael Wilson.
} 
de parcelas se definiam. A atividade política é a que desloca um corpo do lugar que lhe era designado ou muda a destinação de um lugar; ela faz ver o que não cabia ser visto, faz ouvir como discurso o que só era ouvido como barulho (RANCIÈRE, 2005, p. 42).

Em outras palavras, a imagem convencional do negro como lascivo, preguiçoso, tolo, hipersexualizado, ingênuo ou passivo, pelo viés homogeneizante do signo saussuriano assume, resultante de um período sócio-histórico diverso e de seus novos paradigmas, um caráter político que redistribui saberes, neste caso, por meio da arte como forma de deslocamento, incômodo, deslumbramento e, sobretudo, ressignificação. Nos filmes citados, tem-se uma temporalidade de protagonismo para os afroamericanos, em uma esfera diametralmente oposta à anterior.

Pode-se dizer que este processo ininterrupto de construção de sentidos imbrica o esquema sígnico bakhtiniano, o qual concebe o significado como categoria subjacente ao contexto sócio-histórico do diretor/produtor/roteirista/espectador, etc. Em nossa pesquisa, notamos que se o filme sobre a trajetória negra é realizado por uma pessoa negra, há ênfase na coragem e na resiliência de seu povo, quer durante as rebeliões abolicionistas, as marchas pelos Direitos Civis, os segregados do Jim Crow, os confrontos com a KuKluxKlan, quer no combate a qualquer outra sorte de opressão. Em contrapeso, quando o realizado ré branco, há uma exaltação da valentia de um personagem branco, na defesa da causa negra, pois ele acredita na conciliação do povo estadunidense (SILVA, 2017, p. 141-144). À guisa de ilustração, apropriamo-nos do esquema de Souza (2004, p. 119) sobre o signo bakhtiniano, ao seu turno, uma reinterpretação do signo de Saussure, acrescido dos referentes contextuais (intérprete, sujeito e seu locus de enunciação):

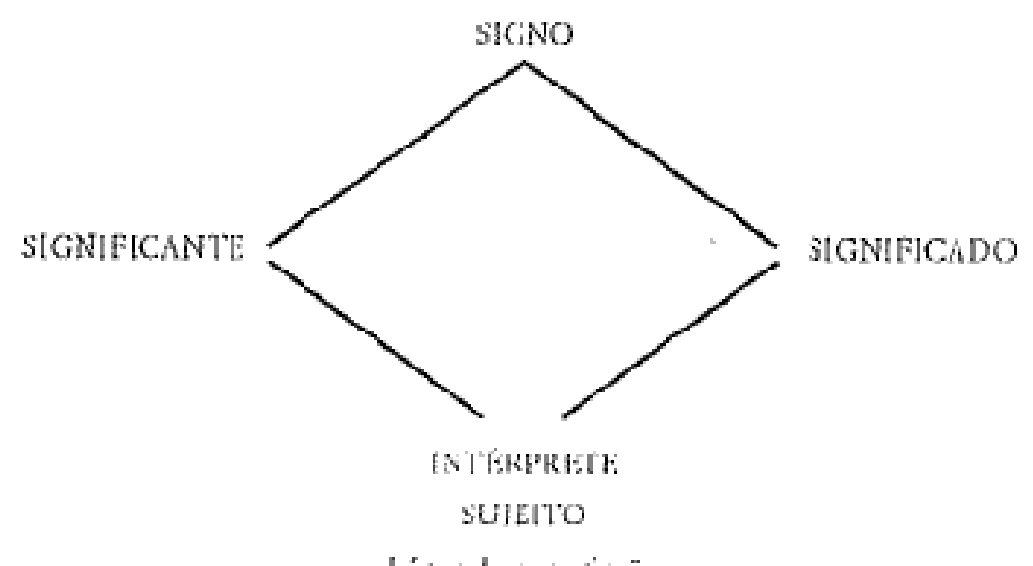

l.ŕc แช de tnunciaçān

Fonte: SOUZA (2004, p. 119). 
De acordo com a nossa interpretação do diagrama de Souza, a desconformidade na narrativa de diretores negros, em relação às mesmas histórias contadas por brancos é evidente, mas vale a ressalva de que a maioria dos filmes dirigidos por negros ainda conta com o dinheiro de produtores brancos, a exemplo de Doze anos de escravidão de Steve McQueen, na direção e Brad Pitt, na produção (SILVA, idem). Em filmes assim, o branco também aparece para ajudar o negro nos conflitos raciais, como explicitamos abaixo:

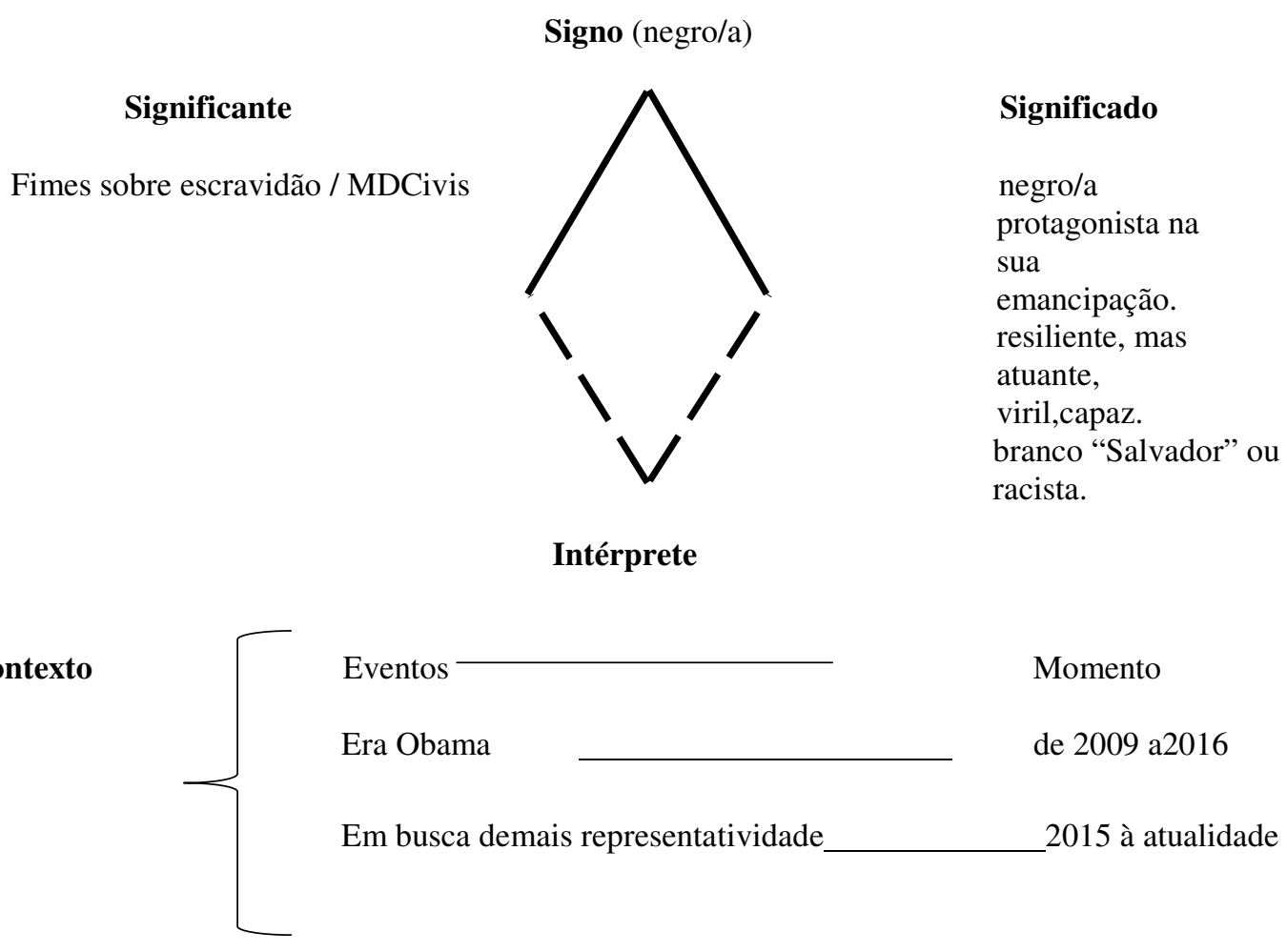

Fonte: SILVA (2017, p. 144).

Resta-nos saber se a proeminência de diretores negros e suas temáticas pedagógicas e reivindicatórias persistirão no governo de Donald Trump. Se depender das redes sociais, sim, visto que a pouca representatividade destes filmes nas premiações de 2015 e 2016 ocasionou manifestos de grande repercussão, a exemplo do \#oscarsowhite.

O rompimento da representação hegemônica visa uma redistribuição de sentidos estéticos e políticos mais equânime e, por consequência, menos desigual no mundo vivido. Quando voltamos nosso olhar para questões de gênero, por exemplo, 
constatamos que a desigualdade é mais abrangente, pois intersecciona opressões como explica Collins:

Primeiro, o pensamento feminista negro promoveu uma mudança paradigmática fundamental na maneira como pensamos sobre as relações injustas de poder. Ao abraçar um paradigma de interseção de opressões de raça, classe, gênero, sexualidade e nação, bem como de agência negra feminina individual e coletiva dentro deles, o pensamento feminismo negro reconceitualiza as relações sociais de dominação e resistência (COLLINS, 2000, p. 273).

A socióloga brasileira Sueli Carneiro, por sua vez, nos atualiza com mais um tipo de violência interseccional, a "estética", posto que impõe padrões étnicos de beleza à mulher negra:

\begin{abstract}
Em relação ao tópico da violência, as mulheres negras realçaram uma outra dimensão do problema. Tem-se reiterado que, para além da problemática da violência doméstica e sexual que atingem as mulheres de todos os grupos raciais e classes sociais, há uma forma específica de violência que constrange o direito à imagem ou a uma representação positiva, limita as possibilidades de encontro no mercado afetivo, inibe ou compromete o pleno exercício da sexualidade pelo peso dos estigmas seculares, cerceia o acesso ao trabalho, arrefece as aspirações e rebaixa a autoestima. Esses são os efeitos da "hegemonia da branquitude" no imaginário social e nas relações sociais concretas" (CARNEIRO, 2003, p. 122).
\end{abstract}

Por fim, as práticas de Letramento Crítico envolvem sempre uma relação euoutro. Como sustenta Souza (2016), ao procurar redefini-las, é preciso que o aprendiz aprenda a "ler se lendo" e descubra que seu mundo, seus valores e seus significados se originaram na coletividade:

Isso significa que já não basta entender o letramento crítico como um processo de revelar ou desvelar as verdades de um texto construídas e tendo origem no contexto do autor do texto. Entendemos agora que o processo é mais amplo e complexo: tanto o autor quanto o leitor estão no mundo e com o mundo. Ambos - autor e o leitor -são sujeitos sociais cujos "eus" se destacaram de e tiveram origem em coletividades sócio-históricas de "nãoeus"; isso não apenas cria um sentido de identidade e pertencimento para o sujeito social, mas também uma consciência histórica (SOUZA, 2016, p. 03).

Em consonância com Souza, Vattimo e Zabala (2011) propõem o enfraquecimento de qualquer metafísica ou fundamento nocivos sobre o Outro, reforçados pelos sistemas de produção simbólicos, a exemplo da mídia audiovisual. Se a violência da representação contra os afro-americanos deu-se, mormente, pela figuração estereotipada de personagens irrelevantes ou que apenas ancoravam protagonistas brancos, tal regime hegemônico sofre, com o passar dos anos, rupturas 
que suscitaram representações mais positivas. Isto só é ou foi possível, em decorrência de contextos sócio-históricos que ressignificaram verdades pré-estabelecidas. A fim de realizarmos um trabalho com o letramento crítico (visual e racial), reiteramos Souza (2016), para quem uma pós-crítica só pode ser aquela que busca a origem sóciohistórica dos significados que atribuímos aos textos.

O estudo do cinema, em sala de aula, pode se configurar como território decolonizador, a partir do momento que tanto crenças totalizantes como conceitos binários de "centro e margem", "mais civilizado e menos civilizado", 'igual e desigual" etc. são problematizados (MONTE MÓR, 2018), diminuindo distâncias e injustiças sociais. O professor de cultura, língua e literatura estrangeira, cuja práxis se alinha a uma proposta social, transdisciplinar e transversal e que pretende analisar filmes com os seus alunos, tem de se inteirar de conteúdos outros que não somente os da sua área específica de atuação. Além de pedagogias educacionais críticas, é importante estudar História dos Estados Unidos, história da representação fílmica, epistemologias decoloniais, de gênero e de raça e, mais especialmente, o cinema e suas convenções enquanto linguagem multimodal. Logo, sugerimos que o aluno (re)pense como as relações de poder são firmadas, a relevância dos papéis, de acordo com a raça, o gênero, a classe social, econômica, cultural, religiosa, etária etc. dos personagens; o quanto esta figuração é ou não estereotipada, discriminatória, subalternizada, bem como a questão inevitável sobre a importância da representatividade de determinados grupos no audiovisual. Por fim, podemos traçar um paralelo com o que é dominante em nosso país, em que instâncias há racismo, machismo e demais hierarquias de desigualdade e com qual frequência estas discursividades aparecem nas mídias. Tal investigação ultrapassa o espaço escolar, ou seja, implica também em sondar o que a(s) comunidade(s) pensa(m) sobre o assunto a ser discutido, em um exercício de expansão interpretativa, como prescreve Monte Mór (2018).

Espera-se que o resultado seja a multiplicidade de percepções, de si e do outro, re-partilhas mais igualitárias dos sentidos, em um espaço dissensual; porém, sempre em prol da formação de identidades menos violentas. 


\section{REFERÊNCIAS}

BOURDIEU, P. Surl'État. Coursau Collège de France (1989-1992). Paris: Raisons d'Agir/Seuil, 2012.

CARNEIRO, S. "Mulheres em movimento" in Estudos Avançados 17, 2003.

COLlinS, P. H. Black Feminist Thought: Knowledge, Consciousness, and the Politics of Empowerment, New York, London: Routledge, 2000.

FOUCAULT, M. Vigiar e punir: nascimento da prisão; trad. Raquel Ramalhete. Ed. 34. Petrópolis, RJ: Vozes, 2007.

GIROUX, H. Breaking in to the Movies: Film and the Culture of Politics. Malden: Blackwell Publishers, 2002.

MOHANTY, S. P. Political Criticism and the Challenge of Otherness. In: MOHANTY, S. P. Literary Theory and the claims of History: postmodernism, objectivity, multicultural politics. Ithaca and London: Cornell University Press, 1997.

MONTE MÓR, W. Letramentos críticos e expansão de perspectivas: diálogo sobre práticas. In: JORDÃO, C.; MARTINEZ, J. Z.; MONTE MÓR, W. (Orgs.). Letramentos em Prática na formação inicial de Professores de Inglês, Campinas, SP: Pontes Editora, 2018, p. 315-335.

RANCIÈRE, J. A partilha do sensível: estética e política. Tradução: Mônica Costa Netto. São Paulo: EXO experimental, Ed. 34, 2005.

SOUZA, L. M. T. Hibridismo e tradução cultural em Bhabha. In: ABDALA JÚNIOR, B. (Org.). Margens da cultura: mestiçagem, hibridismo \& outras misturas. São Paulo: Boitempo Editorial, 2004, p.113-133.

MENEZES DE SOUZA, L. M. T. Para uma redefinição de letramento crítico: conflito e produção de significação. In: MACIEL, R.F.; ARAÚJO, V.A. (Orgs.). Formação de Professores de Línguas: ampliando perspectivas. Jundiaí: Paco Editorial, 2011, p. 128140.

SILVA, A. A. C. O sensível (não) partilhado: a violência poética e política da (ir)representação do negro em Hollywood. Tese de Doutorado, Faculdade de Filosofia, Letras e Ciências Humanas, Universidade de São Paulo, São Paulo, 2017.

VATtiMO, G.; ZABALA, S. Hermeneutic Communism - From Heidegger to Marx. Columbia University Press, New York, 2011. 